\title{
Long Term Safety and Efficacy of Single-Incision Sling versus Mid-Urethral Sling in the Treatment of Stress Urinary Incontinence
}

\author{
Martin Huser ${ }^{1}$, Robert Hudecek ${ }^{1}$, Ivan Belkov ${ }^{1}$, Ivan Horvath ${ }^{2}$, Jíri Jarkovský ${ }^{3}$, and \\ Samuel Tvarozek ${ }^{1}$ \\ ${ }^{1}$ Brno University Hospital and Masaryk University Medical School, Department of \\ Obstetrics and Gynecology \\ ${ }^{2}$ Masaryk University Medical School, Department of Obstetrics and Gynecology \\ ${ }^{3}$ Institute of Biostatistics and Analyses, Masaryk University Medical School
}

May 5, 2020

\begin{abstract}
Objective: To compare long term efficacy and safety of an innovative single incision sling (SIS) with the inside-out transobturator sling (TOT) in the treatment of female stress urinary incontinence (SUI). Design: randomized controlled trial. Setting: single tertiary referral urogynecology center. Population: women with pure urodynamic SUI. Methods: randomized to either an SIS or TOT and followed-up for four years. Main Outcome Measures: The primary outcomes were objective cures defined with a negative cough stress test and subjective cure reported via patient's satisfaction scale. Secondary outcomes involved surgery complications including re-operations, postoperative de-novo urgency, and impact on patient quality of life. Results: The objective $(86.4 \%$ vs. $83.1 \% ; 95 \%$ CI $0.30-2.02 ; \mathrm{p}=0.635)$ and subjective cure rates $(83.3 \%$ vs. $80.0 \% ; 95 \%$ CI 0.33-1.94; $\mathrm{p}=0.657$ ) were similar with the SIS and TOT groups. Both procedures were associated with low complication rates. Repeated surgery rates owing to recurrent SUI were $7.6 \%$ in SIS and $6.3 \%$ in TOT groups, respectively. Overall mesh exposure rate was $2.3 \%$ for both groups. Incidence of de-novo urgency didn't vary between TOT and SIS patients. Both groups registered a significant quality of life improvement. Conclusions: Following long term follow-up, anti-incontinence SIS surgery proved noninferior to inside-out TOT procedure in terms of objective and subjective cure rates. Funding: supported by Czech Republic Ministry of Health, No. FNBr65269705 Keywords: Stress urinary incontinence; mid-urethral sling; single incision sling; efficacy; patient-reported outcomes; randomized controlled trial Clinical Trial Registration: ClinicalTrials.gov, NCT02506309
\end{abstract}

\section{Long Term Safety and Efficacy of Single-Incision Sling versus Mid-Urethral Sling in the Treat- ment of Stress Urinary Incontinence}

Martin Huser MD, PhD (1, 2), Robert Hudecek MD, PhD (1, 2), Ivan Belkov MD (1, 2), Ivan Horvath (2), Jiri Jarkovsky MA (3), Samuel Tvarozek MD (1)

1. Brno University Hospital, Department of Obstetrics and Gynecology, Jihlavska 20, 62500 Brno, Czech Republic

2. Masaryk University Medical School, Department of Obstetrics and Gynecology, Kamenice 753/5, 625 00 Brno, Czech Republic

3. Institute of Biostatistics and Analyses, Masaryk University Medical School, Kamenice 126/3, 62500 Brno, Czech Republic

Corresponding author: 
Robert Hudecek, MD, PhD Brno University Hospital, Department of Obstetrics and Gynecology, Jihlavska 20,625 00 Brno, Czech Republic, tel. +420 605580 606,185124@mail.muni.cz

A short (running) title (50 characters including spaces, max. 50)

Innovations in stress urinary incontinence therapy

Tweetable abstract (108 characters, max. 110)

Following long term follow-up, anti-incontinence SIS surgery proved non-inferior to inside-out TOT procedure.

Abstract (230 words, 250 max.)

Objective: To compare long term efficacy and safety of an innovative single incision sling (SIS) with the inside-out trans-obturator sling (TOT) in the treatment of female stress urinary incontinence (SUI).

Design: randomized controlled trial.

Setting: single tertiary referral urogynecology center.

Population: women with pure urodynamic SUI.

Methods: randomized to either an SIS or TOT and followed-up for four years.

Main Outcome Measures: The primary outcomes were objective cures defined with a negative cough stress test and subjective cure reported via patient's satisfaction scale. Secondary outcomes involved surgery complications including re-operations, postoperative de-novo urgency, and impact on patient quality of life.

Results : The objective ( $86.4 \%$ vs. $83.1 \% ; 95 \%$ CI $0.30-2.02 ; \mathrm{p}=0.635)$ and subjective cure rates $(83.3 \%$ vs. $80.0 \%$; $95 \%$ CI $0.33-1.94 ; \mathrm{p}=0.657)$ were similar with the SIS and TOT groups. Both procedures were associated with low complication rates. Repeated surgery rates owing to recurrent SUI were $7.6 \%$ in SIS and $6.3 \%$ in TOT groups, respectively. Overall mesh exposure rate was $2.3 \%$ for both groups. Incidence of de-novo urgency didn't vary between TOT and SIS patients. Both groups registered a significant quality of life improvement.

Conclusions: Following long term follow-up, anti-incontinence SIS surgery proved non-inferior to inside-out TOT procedure in terms of objective and subjective cure rates.

Funding: supported by Czech Republic Ministry of Health, No. FNBr65269705

Keywords: Stress urinary incontinence; mid-urethral sling; single incision sling; efficacy; patient-reported outcomes; randomized controlled trial

Clinical Trial Registration: ClinicalTrials.gov, NCT02506309

\section{Introduction}

Urinary incontinence (UI) is a common condition that affects $35-50 \%$ of women during their lifetime ${ }^{1}$. Patients with UI have a significantly poorer quality of life than their continent counterparts ${ }^{2}$. Stress urinary incontinence (SUI) represents the most common UI type, and its pathophysiology has consistently improved during the past two decades. Based on the integral theory of continence, Petros and Ulmsten in 1995 proposed their mid-urethral sling concept and introduced the original retropubic tension-free vaginal tape (TVT) technique ${ }^{3}$. Mid-urethral slings (MUS) now represent a gold standard in the treatment of female stress urinary incontinence (SUI) ${ }^{4}$. Second generation inside-out trans-obturator slings (TVT-O) or the later outside-in trans-obturator (TOT) slings have proven to be as effective as retropubic TVT with fewer major complications ${ }^{5}$. A third generation of the MUS inserted through a single vaginal incision (SIS) has become a means to overcome significant post-operative groin pain. Novel types of SIS with a more reliable and adjustable anchoring mechanism can assure adequate long-lasting attachment to the obturator membrane $(\mathrm{OM})^{4}$. 
U.S. Food and Drug Administration (FDA) notifications regarding vaginally placed meshes have, nonetheless, definitely affected SUI surgical treatment, and studies are now directed at what type of MUS is superior to traditional procedures ${ }^{6}$. Recent literature reiterates well established MUS safety and effectiveness, nevertheless, data regarding SIS still needs additional evidence, especially concerning the long term ${ }^{7}$. Although some modern "third generation" SIS (MiniArc, Ajust), exhibited similar efficiency when compared to standard MUS, these commonly used products are no longer on the market ${ }^{8}$. Our research group previously reported one year results of a randomized controlled trial (RCT) comparing the innovative fixation SIS (Ophira, Promedon) with the inside-out TOT (Gynecare TVT Obturator System, Ethicon). In short term follow-up, we determined that an Ophira SIS is non-inferior to Gynecare TOT with respect to efficacy and, moreover, with significantly less groin pain during the early postoperative period. Both methods were also safe and effective in terms of postoperative urgency and life quality improvement ${ }^{9}$. Recently published first long term results evaluating Ophira SIS efficacy are also promising, although randomized comparison with standard MUS is still lacking ${ }^{10},{ }^{11}$.

In this study, our goal was to evaluate efficacy and safety of the Ophira SIS in comparison with the inside-out TOT during a long term follow-up. Primary RCT outcomes were defined via SUI objective and subjective cure rate evaluations four years following MUS surgery. Early and late operative complications, need for recurrent surgery, quality of life, and urgency incontinence occurrence were selected as secondary study endpoints.

\section{Methods}

\section{Participants}

A prospective randomized controlled trial (RCT) was undertaken via Czech tertiary referral at the Brno University Hospital Urogynecology Center from January 2015 thru December 2019. This non-blinded study involved Caucasian (central European) women with pure urodynamic SUI confirmed during cystometry by a positive standardized cough stress test (CST) with urinary bladder filling of $250 \mathrm{ml}$ in lithotomy position. Patients with urgency or predominant urgency incontinence, intrinsic sphincter deficiency (MUCP $<20$ $\mathrm{cmH2O}$ ), and pelvic organ prolapse (POP-Q $>2$ ) were excluded from the study. Further exclusion criteria were previous SUI surgery or pelvic organ prolapse (POP) surgery and presence of other pelvic organ pathology. Study was approved by our university hospital Ethical Review Board. Written informed consent for study enrollment was collected from all participants. The study was supported by the National Ministry of Health (Project Number FNBr65269705). The funder (through their peer review and funding board review process) approved the study proposal but had no role in the collection, analysis, or interpretation of data, or writing of the report.

\section{Randomization and treatment}

Before surgery, all eligible patients completed a short International Consultation on Incontinence Questionnaire (ICIQ-SF) to measure the impact of patient's symptoms on quality of life, where ratings ranged from 0 (no reduction in life quality) to 21 points ${ }^{2}$. Patients were randomized by envelope technique at the time of surgery to either a TOT or SIS anti-incontinence procedure. For the TOT procedure, the inside-out Gynecare TVT Obturator System (Ethicon) was used. The SIS procedure was performed with an Ophira (Promedon) surgical kit. Patients in both TOT and SIS study groups were treated with standardized surgical techniques in accordance with manufacturer instructions ${ }^{12}$. All TOT surgeries were performed by one senior surgeon with the experience of more than 200 previous surgeries. All SIS surgeries were undertaken by another specialist with practice of more than 200 previous MUS surgeries including at least 30 SIS insertions. Every procedure was carried out under general anesthesia. The urinary Foley catheter was removed six hours after surgery, and patients were discharged the next day. No planned concomitant surgery or routine intraoperative cystoscopy were performed.

\section{Outcomes}

Follow-up visits four years after surgery were all done by an independent clinician and included evaluations 
of objective and subjective cure as primary study outcomes. Objective cure was defined as absence of urinary leakage in standardized CST. Subjective cure was assessed with a Patient Global Impression of Improvement (PGI-I) form utilizing a seven-point satisfaction scale (1-7) ${ }^{13}$. Cure was defined as a response of 1 "very much improved", 2 "much improved", or 3 "improved". Secondary outcomes included changes in quality of life questionnaire scores (ICIQ-SF) and postoperative de-novo urgency occurrence measured via a Patient Perception of Intensity of Urgency Scale (PPIUS) ranging from 0 (no urgency) to 4 (urge incontinence) ${ }^{14}$.

All major intraoperative and postoperative complications were recorded according to joint ICS/IUGA classification related to the insertion of a prosthesis distinguishing urinary tract compromise or postoperative urine retention, infection, abscess, rectum or bowel perforation, skin or musculoskeletal damage, and heavy bleeding including hematoma or systemic patient compromise ${ }^{15}$.

Tape exposure was defined as mesh visualized through separated epithelium, whereas tape extrusion as gradual passage of mesh out of the body tissue. Furthermore, all surgical re-interventions were reported differentiating procedures performed because of primary surgery failure and procedures related to mesh or surgery complications. All definitions are in keeping with the recommendations of IUGA and ICS ${ }^{16}$.

\section{Statistical analysis}

The sample size calculation was implemented presuming an expected objective cure rate of minimum 80 $\%$ for both patient groups. A minimum sample size of 64 patients was required for each group to detect a difference of $13 \%$ in cure rates between the two procedures, with $80 \%$ power and false non-match rate (alpha) of 0.05 . Assuming a follow-up loss rate of $24 \%$ after four years, a total enrolment of 168 patients was projected.

Absolute and relative frequencies were computed for categorical variables; mean \pm standard deviation for continuous variables. Statistical significance of differences between groups of patients was analyzed by a Fisher exact test for categorical variables and the Mann-Whitney $U$ test for continuous and nominal variables. Odds ratio and its $95 \%$ confidence interval was adopted for the description of group influence on binary endpoints occurrence. The SPSS Statistics (IBM) software was used, and $\mathrm{p}<0.05$ was considered statistically significant.

\section{Results}

The Consolidated Standards of Reporting Trials (CONSORT) flow diagram covering all patients is shown in Figure 1. From 192 eligible patients, a total of 168 patients (87.5\%) were randomized into SIS (n=84) and TOT groups $(\mathrm{n}=84)$. Finally, 66 patients $(78.6 \%)$ in the SIS group and 64 patients $(76.2 \%)$ in the TOT group completed the 5-year follow-up.

There were no significant differences in age, body mass index, parity, or pre-operative quality of life assessment between both comparative study groups (Table 1). Objective and patient-reported outcomes four years after surgery are detailed in Table 2. The SIS surgery was non-inferior to standard TOT procedure in terms of objective ( $86.4 \%$ vs. $83.1 \%$; $95 \%$ CI $0.30-2.02 ; \mathrm{p}=0.635)$ and subjective cure rates $(83.3 \%$ vs. $80.0 \% ; 95 \%$ CI 0.33-1.94; $\mathrm{p}=0.657$ ). Furthermore, the comparison of urgency incontinence incidence and quality of life investigation between TOT and SIS groups didn't indicate statistically significant differences. Mean change in ICIQ-SF scores before and after surgery was 11.6 \pm 3.0 in the SIS group and $11.4 \pm 3.2$ in the SIS group.

Table 3 notes intraoperative and postoperative complications and need of re-intervention in both groups. No severe intraoperative complications occurred in either group. Five patients had early postoperative urine retention (4BbT2S3), and two of them successfully recovered after temporary 24-hour catheterization. Another three (2x SIS, 1x TOT) finally required mesh surgical loosening the second or third day after surgery (4BeT2S3). Three patients out of $130(2.3 \%)$ were identified with mesh exposure/extrusion. The mesh exposure rate in all cases (1x SIS, 2x TOT) was [?] $1 \mathrm{~cm}$ and had been diagnosed later than 12 months after surgery, always in the vaginal area of suture line (2AaT4S1). Women were successfully managed conservatively with topical estrogen therapy excepting one case in TOT group. That patient underwent surgical overlap of exposure by vaginal mucosa without the need for tape excision. During the 5 -year follow-up, nine 
out of 130 women (6.9\%) in both study groups (5x SIS, 4x TOT) required further surgical treatment owing to recurrent SUI. In all patients a retropubic sling was placed successfully during the third or fourth year of follow-up.

\section{Discussion}

\section{Main findings}

SIS usage within the SUI treatment is still controversial, rendering a critical need for additional studies that will elucidate its place in surgical management. Few well designed prospective studies have reported encouraging short and medium term SIS outcomes ${ }^{17},{ }^{18},{ }^{19}$, although other research findings substantiated opposite results ${ }^{20}$. Overall analysis of our four year follow-up RCT primarily demonstrates SUI surgery non-inferiority with adjustable SIS in relation to inside-out TOT regarding both subjective and objective cure. In studies evaluating efficacy and success, there is currently a trend worldwide to consider subjective findings more relevant that objective outcomes. Our study results recognize higher objective cure rates than subjective. A possible explanation of this fact could be that patients during CST maximize focus on optimum pelvic floor contraction, rendering this situation physical vice physiological. Another factor is the influence of urgency which can negatively affect patient's overall satisfaction during subjective evaluation.

\section{Strengths and Limitations}

Our trial's strength is the thorough standardization of surgical technique with all procedures implemented by the same experienced urogynecology surgeon. Furthermore, our trial employed a prospective randomized study design together with long term follow-up. Subsequent data analysis evaluated both objective and subjective outcomes via validated methods. However, one limitation might be that neither patients nor surgeons were blinded to the procedure performed.

Loss to follow-up rates reported in our trial was $21.4 \%$ in SIS group and $23.8 \%$ in TOT group. These rates were better or equivalent to previously published randomized trials with two or three years follow up time $20,{ }^{17}$. Within our four year observation interval, it was challenging for both patients and physicians to maintain commitment. The IUGA/ICS classification system was used to standardize complication rates. Tape exposure rates (1.5\% in SIS and $3.1 \%$ in TOT groups) and lower urinary tracts symptoms including urine retention (3.0\% in SIS and 4.6\% in TOT groups) were in accordance with other reports ${ }^{20},{ }^{17},{ }^{18}$. Although not statistically significant, our mini sling surgeries were associated with slightly more revision procedures owing to SUI recurrence compared to TOT (7.6\% vs. $6.3 \%)$.

\section{Interpretation}

The SIS used in our study was found comparable in the long term to an inside-out TOT sling concerning both subjective (83.3\%) and objective cure rates (86.4\%). Previously published RCTs determined that another SIS system (MiniArc) has comparable subjective and objective cure rates ( $86 \%$ and $89 \%$, respectively), although after only three years follow-up ${ }^{17}$. Similar mid-term results were affirmed in a study evaluating the Contasure-needleless SIS system reported by Dogan et al. ${ }^{18}$. Conversely, another RCT specifically assessing Ophira SIS efficacy after three years indicated inferiority of this sling in comparison with TOT in both subjective and objective cure rates (68.3\% vs. $85.4 \%)$. Possible explanation for this inconsistency might be inclusion of complex cases with prior anti-incontinence surgery and adoption of rigorous objective cure criteria including CST along with a pad weight test ${ }^{20}$. Long term follow-up (over three years) data evaluating SIS are available only from one retrospective observational study, in which Lo et al reported MiniArc SIS efficacy with $84.7 \%$ objective and $80.0 \%$ subjective cure rates ${ }^{21}$.

It is worth acknowledging that not all SIS are equal. They differ in regards to exact insertion technique, sling material, and, especially, their anchoring system. The Ophira SIS is equipped with a sophisticated anchor system, which, in an obturator membrane, retains the power of 18-20 Newtons. Both anchors include special release stitches which allow a surgeon to select proper tape tension ${ }^{12}$. Currently, some previously referenced SIS are no longer commercially available. Nevertheless, we feel that our results are generally applicable, at 
least for slings with a well-developed anchoring mechanism applied in urogynecology centers with sufficient expertise in SUI surgery.

The European Association of Urology 2018 guidelines note that, for one year, there is no difference in efficacy between available SIS and conventional MUS. However, not all SIS have been subjected to RCT evaluation, and it may be unsafe to assume that all collectively are technically similar devices ${ }^{22}$. Likewise, the most recent Cochrane review of SIS placement in patients with SUI concludes that there is still insufficient evidence to reveal a difference in incontinence rates with a SIS compared with trans-obturator MUS. Significant differences were observed with postoperative and long-term pain rates and with duration of the operation

${ }^{4}$. Our study's encouraging results suggest that modern well anchored and adjustable SIS have promising treatment potential - even in the long term!

\section{Conclusion}

Based on our long term follow-up results, the Ophira SIS had similar cure rates to the trans-obturator MUS among women undergoing surgery for SUI. This is the first study assessing long-term outcomes following randomization to a SIS and standard MUS treatment. However, results obtained with one SIS cannot be applied to another, so external validation studies, therefore, are also needed. We believe our results should be included in future meta-analyses to foster better understanding of the role of SIS systems in SUI management.

\section{Acknowledgement}

The authors wish to thank the women who participated in the study; and the staff who facilitated the recruitment, treatment and follow-up of study participants.

\section{Disclosure of Interests}

The authors declare no personal interests, financial or non-financial, relating to this research and its publication. This is not the industry-sponsored research, all authors have maintained ethical and transparent publication practices.

\section{Contribution to Authorship}

MH designed the study and drafted the manuscript. MH and IB performed all surgical interventions. RH and IH followed and interviewed the patients. JJ processed, collated and analyzed acquired clinical data. ST helped with manuscript writing and provided clinical data quality control. All authors critically reviewed the manuscript and approved the final version.

\section{Details of Ethics Approval}

Study was approved by Brno University Hospital Ethical Review Board on 21 ${ }^{\text {st }}$ January 2015 (reference number 24/2015).

\section{Funding}

Financially supported by the Czech Republic Ministry of Health - project FNBr65269705.

\section{References}

1. Minassian VA, Stewart WF, Wood GC. Urinary incontinence in women: variation in prevalence estimates and risk factors. Obstet Gynecol. 2008;111:324-31.

2. Krhut J, Gartner M, Mokris J, Horcicka L, Svabik K, Zachoval R, et al. Effect of severity of urinary incontinence on quality of life in women. Neurourol Urodyn. 2018;37:1925-30.

3. Petros PE, Ulmsten UI. An integral theory of female urinary incontinence. Experimental and clinical considerations. Acta Obstet Gynecol Scand Suppl. 1990;153:7-31.

4. Nambiar A, Cody JD, Jeffery ST, Aluko P. Single-incision sling operations for urinary incontinence in women. Cochrane Database Syst Rev. 2017;7:CD008709. 
5. Imamura M, Hudson J, Wallace SA, MacLennan G, Shimonovich M, Omar MI, et al. Surgical interventions for women with stress urinary incontinence: systematic review and network meta-analysis of randomised controlled trials. BMJ [Internet]. 2019 [citovan 18. prosinec 2019];365. Dostupne z: https://www.bmj.com/content/365/bmj.11842

6. Nager CW. Midurethral slings: evidence-based medicine vs the medicolegal system. Am J Obstet Gynecol. 2016;214:708.e1-708.e5.

7. U.S. Food and Drug Administration. Considerations about Surgical Mesh for SUI [Internet]. FDA. 2019 [citovan 1. červenec 2019]. Dostupné z: http://www.fda.gov/medical-devices/urogynecologic-surgical-meshimplants/considerations-about-surgical-mesh-sui

8. Masata J, Svabik K, Zvara K, Hubka P, Toman A, Martan A. Comparison of the efficacy of tension-free vaginal tape obturator (TVT-O) and single-incision tension-free vaginal tape (Ajust ${ }^{\mathrm{TM}}$ ) in the treatment of female stress urinary incontinence: a 1-year follow-up randomized trial. Int Urogynecology J. 2016;27:1497505.

9. Jurakova M, Huser M, Belkov I, Janku P, Hudecek R, Stourac P, et al. Prospective randomized comparison of the transobturator mid-urethral sling with the single-incision sling among women with stress urinary incontinence: 1-year follow-up study. Int Urogynecology J. 2016;27:791-6.

10. Mira Gon L, Zanettini Riccetto CL, Citatini de Campos CC, Iamashita Voris BR, Reis LO, Rodrigues Palma PC. Mini-Sling Ophira at 8 Years Follow-Up: Does It Sustain Results? Urol Int. 2019;102:326-30.

11. Golbasi C, Taner CE, Golbasi H. Long-term outcomes and quality of life effects of single incision mini sling procedure in stress urinary incontinence patients. Eur J Obstet Gynecol Reprod Biol. 2019;234:10-3.

12. Palma P, Riccetto C, Bronzatto E, Castro R, Altuna S. What is the best indication for single-incision Ophira Mini Sling? Insights from a 2-year follow-up international multicentric study. Int Urogynecology J. 2014;25:637-43.

13. Yalcin I, Bump RC. Validation of two global impression questionnaires for incontinence. Am J Obstet Gynecol. 2003;189:98-101.

14. Cartwright R, Srikrishna S, Cardozo L, Robinson D. Validity and reliability of the patient's perception of intensity of urgency scale in overactive bladder. BJU Int. 2011;107:1612-7.

15. Haylen BT, Freeman RM, Swift SE, Cosson M, Davila GW, Deprest J, et al. An International Urogynecological Association (IUGA)/International Continence Society (ICS) joint terminology and classification of the complications related directly to the insertion of prostheses (meshes, implants, tapes) and grafts in female pelvic floor surgery. Neurourol Urodyn. 2011;30:2-12.

16. Haylen BT, Maher CF, Barber MD, Camargo S, Dandolu V, Digesu A, et al. An International Urogynecological Association (IUGA) / International Continence Society (ICS) joint report on the terminology for female pelvic organ prolapse (POP). Int Urogynecology J. 2016;27:165-94.

17. Schellart RP, Zwolsman SE, Lucot J-P, de Ridder DJMK, Dijkgraaf MGW, Roovers J-PWR. A randomized, nonblinded extension study of single-incision versus transobturator midurethral sling in women with stress urinary incontinence. Int Urogynecology J. 2018;29:37-44.

18. Dogan O, Kaya AE, Pulatoglu C, Basbug A, Yassa M. A randomized comparison of a single-incision needleless (Contasure-needleless (B) mini-sling versus an inside-out transobturator (Contasure-KIM@) midurethral sling in women with stress urinary incontinence: 24-month follow-up results. Int Urogynecology J. 2018;29:1387-95.

19. Morán E, Pérez-Ardavín J, Sánchez JV, Bonillo MA, Martínez-Cuenca E, Arlandis S, et al. Mid-term

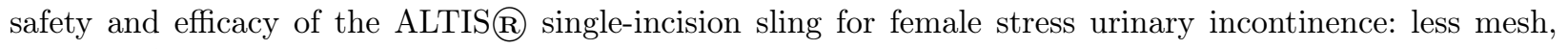
same results. BJU Int. 2019;123:E51-6. 
20. Pascom ALG, Djehdian LM, Bortolini MAT, Jarmy-Di Bella ZIK, Delroy CA, Tamanini JTN, et al. Randomized controlled trial comparing single-incision mini-sling and transobturator midurethral sling for the treatment of stress urinary incontinence: 3-year follow-up results. Neurourol Urodyn. 2018;37:2184-90.

21. Lo T-S, Chua S, Kao CC, Uy-Patrimonio MC, Ibrahim R, Tan YL. Five-Year Outcome of MiniArc Single-Incision Sling Used in the Treatment of Primary Urodynamic Stress Incontinence. J Minim Invasive Gynecol. 2018;25:116-23.

22. European Association of Urology. Guidelines on Urinary Incontinence in Adults [Internet]. Uroweb. 2019 [citován 19. prosinec 2019]. Dostupné z: https://uroweb.org/guideline/urinary-incontinence/\#4

\section{Tables}

\section{Table 1}

Pre-operative patient characteristics

\begin{tabular}{llll}
\hline & SIS* group $(\mathrm{n}=84)$ & TOT $^{*}$ group $(\mathrm{n}=84)$ & $\mathrm{p} \mathrm{value}^{\text {a }}$ \\
\hline Age (years) & $61.3 \pm 10.0$ & $62.5 \pm 10.4$ & 0.464 \\
$\begin{array}{l}\text { Body mass index } \\
\text { (kg/m2) }\end{array}$ & $28.7 \pm 6.7$ & $29.5 \pm 6.0$ & 0.188 \\
Parity (births/life) & $2.2 \pm 1.2$ & $2.3 \pm 1.1$ & \\
Pre-operative & $14.8 \pm 2.6$ & $14.9 \pm 3.0$ & 0.486 \\
ICIQ-SF* score (0-21) & & & 0.842 \\
\hline
\end{tabular}

a Mann-Whitney U test

* SIS - single incision sling, TOT - trans-obturator tape (sling), ICIQ-SF - International Consultation of Incontinence Questionnaire Short Form

Table 2

Objective and patient-reported outcomes four years after surgery

\begin{tabular}{lllll}
\hline & SIS* group $(\mathrm{n}=66)$ & TOT $^{*}$ group $(\mathrm{n}=64)$ & $\begin{array}{l}\text { Risk difference for } \\
\text { TOT }(95 \% \text { CI })\end{array}$ & p value $^{\text {b }}$ \\
\hline $\begin{array}{l}\text { Objective cure } \\
\text { rates (negative }\end{array}$ & $57(86.4 \%)$ & $54(83.1 \%)$ & $0.78(0.30-2.02)$ & 0.635 \\
$\begin{array}{l}\text { CST*) } \\
\begin{array}{l}\text { Subjective cure } \\
\text { rates (PGI-I*) }\end{array}\end{array}$ & $55(83.3 \%)$ & $52(80.0 \%)$ & $0.80(0.33-1.94)$ & 0.657 \\
$\begin{array}{l}\text { PPIUS* score } \\
(0-4)\end{array}$ & $0.7 \pm 1.0$ & $0.8 \pm 1.1$ & - & 0.508 \\
$\begin{array}{l}\text { Postoperative } \\
\begin{array}{l}\text { ICIQ-SF* score } \\
(0-21)\end{array}\end{array}$ & $3.3 \pm 1.9$ & $3.4 \pm 2.1$ & - & 0.963 \\
Change in & $11.6 \pm 3.0$ & $11.4 \pm 3.2$ & & \\
$\begin{array}{l}\text { ICIQ-SF } \\
\text { pre/postoperative }\end{array}$ & & & - & \\
\hline
\end{tabular}

a determined as "very much improved", "much improved", or "improved"

${ }^{\mathrm{b}}$ Fisher exact test for categorical variables and Mann-Whitney U test for continuous variables 
* SIS - single incision sling, TOT - trans-obturator tape (sling), CST - cough stress test, PGI-I - Patient Global Impression of Improvement, PPIUS - Patient Perception of Intensity and Urgency Scale, ICIQ-SF International Consultation of Incontinence Questionnaire Short Form

Table 3

Major intraoperative and postoperative complications and need of re-intervention

\begin{tabular}{|c|c|c|c|}
\hline & SIS* group $(\mathrm{n}=66)$ & TOT $^{*}$ group $(\mathrm{n}=64)$ & $\mathrm{p}$ value ${ }^{\mathrm{a}}$ \\
\hline \multicolumn{4}{|l|}{$\begin{array}{l}\text { Perioperative } \\
\text { complications }\end{array}$} \\
\hline Infection, abscess & 0 & 0 & $\mathrm{n} / \mathrm{a}$ \\
\hline $\begin{array}{l}\text { Postoperative urine } \\
\text { retention }\end{array}$ & $2(3.0 \%)$ & $3(4.6 \%)$ & 0.742 \\
\hline $\begin{array}{l}\text { Other urinary tract } \\
\text { compromise or } \\
\text { perforation }\end{array}$ & 0 & 0 & $\mathrm{n} / \mathrm{a}$ \\
\hline $\begin{array}{l}\text { Bladder, rectum or } \\
\text { bowel perforation }\end{array}$ & 0 & 0 & $\mathrm{n} / \mathrm{a}$ \\
\hline $\begin{array}{l}\text { Heavy bleeding, } \\
\text { hematoma, systemic } \\
\text { patient compromise }\end{array}$ & 0 & 0 & $\mathrm{n} / \mathrm{a}$ \\
\hline $\begin{array}{l}\text { Tape } \\
\text { exposure/extrusion } \\
\text { Re-intervention }\end{array}$ & $1(1.5 \%)$ & $2(3.1 \%)$ & 0.616 \\
\hline $\begin{array}{l}\text { Urine retention needing } \\
\text { tape loosening }\end{array}$ & $2(3.0 \%)$ & $1(1.6 \%)$ & 0.473 \\
\hline $\begin{array}{l}\text { Tape exposure } \\
\text { requiring re-operation }\end{array}$ & 0 & $1(1.6 \%)$ & 0.324 \\
\hline $\begin{array}{l}\text { Surgery failure needing } \\
\text { re-operation }\end{array}$ & $5(7.6 \%)$ & $4(6.3 \%)$ & 0.914 \\
\hline
\end{tabular}

${ }^{a}$ Fisher exact test

* SIS - single incision sling, TOT - trans-obturator tape (sling)

Figures

Figure 1

Flowchart CONSORT diagram of study enrollment, patient's follow-up and data analysis

Enclosed as separate file 


\section{Figure 1}

Consolidated Standards of Reporting Trials (CONSORT) flow diagram

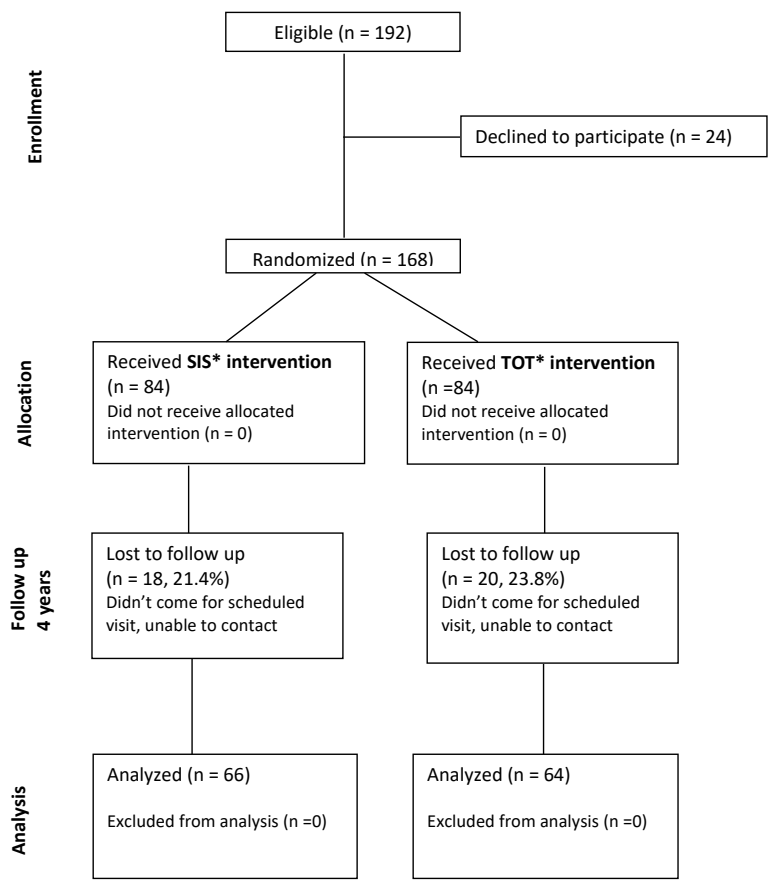

* TOT transobturator sling, SIS single-incision sling 